\title{
Article \\ Numerical Investigating on Representativeness of Tracers in PIV Model Test of Dredged Slurry Treated by Vacuum Preloading
}

\author{
Jiahao Wang ${ }^{1}$, Zunan $\mathrm{Fu}^{2}$, Yanming Yu ${ }^{2}$, Guoshuai Wang ${ }^{2}$, Li Shi ${ }^{2, * \mathbb{D}}$, Zhiying Yuan ${ }^{1}$, Kang Yao ${ }^{1}$ and Jie He ${ }^{1}$ \\ 1 College of Civil Engineering, Zhejiang University of Technology, Hangzhou 310014, China; \\ 2111806035@zjut.edu.cn (J.W.); 2111906014@zjut.edu.cn (Z.Y.); 2111906044@zjut.edu.cn (K.Y.); \\ 2111906045@zjut.edu.cn (J.H.) \\ 2 Huadong Engineering Corporation Limited, Hangzhou 310014, China; fu_zn@hdec.com (Z.F.); \\ yu_ym@hdec.com (Y.Y.); wang_gs@hdec.com (G.W.) \\ * Correspondence: lishi@zjut.edu.cn
}

Citation: Wang, J.; Fu, Z.; Yu, Y.; Wang, G.; Shi, L.; Yuan, Z.; Yao, K.; $\mathrm{He}$, J. Numerical Investigating on Representativeness of Tracers in PIV Model Test of Dredged Slurry Treated by Vacuum Preloading. Appl. Sci. 2021, 11, 9715. https://doi.org/ 10.3390/app11209715

Academic Editor: Nicola Bosso

Received: 26 August 2021

Accepted: 8 October 2021

Published: 18 October 2021

Publisher's Note: MDPI stays neutral with regard to jurisdictional claims in published maps and institutional affiliations.

Copyright: (c) 2021 by the authors. Licensee MDPI, Basel, Switzerland. This article is an open access article distributed under the terms and conditions of the Creative Commons Attribution (CC BY) license (https:// creativecommons.org/licenses/by/ $4.0 /)$.

\begin{abstract}
The vacuum preloading method is commonly adopted for improving the soft ground that the embankment of the railway line is laid on. The PIV (Particle Image Velocimetry) technique is a powerful tool in observing the formation of the soil column, a phenomenon that is unique to the dredged slurry when treated by vacuum preloading. However, it is not clear to what extent the motions of the slurry particles can be represented by the PIV tracers. In this paper, a mesoscopic model has been established by using the CFD-DEM method to reproduce the vacuum consolidation process of the slurry, in which the PVD (Prefabricated Vertical Drain) membrane, the slurry particles, and the tracers are described by the DEM, and the pore water is governed by the CFD method. Eight computational cases that can cover a broad range of material parameters governing the PIV model tests on the dredged slurry have been designed and studied by the established model. The representativeness of the PIV tracer is evaluated by comparing the statistic displacement of the tracer to that of the slurry particles. It is found that for the commonly used tracer, the carbon powder, can reliably represent the particle motions of the slurry since the difference in displacements of the tracer and the slurry particles is smaller than $6.5 \%$ if the diameter ratio between the tracer and the slurry particle is within 1.8 .
\end{abstract}

Keywords: CFD-DEM; dredged slurry; tracer; particle image velocimetry; particle movement

\section{Introduction}

Land scarcity is an emerging problem in developed areas due to the fast-increasing population and economy. Tideland reclamation by dredging slurry into cofferdam is an effective and common way to create new lands and thus to alleviate the land shortage problem. There are several land reclamation sites distributed over the southeastern coastal areas of China. The dredged slurry is generally characterized by fine slurry particles (e.g., the average particle size $d_{50} \leq 5 \mu \mathrm{m}$ ), high water content (e.g., $\geq 1.5$ times the liquid limit), and extremely low strength (e.g., $<5 \mathrm{kPa}$ ) [1]. To improve the new land thus that it can be used by later-on constructions, the vacuum preloading method that involves installing PVDs (Prefabricated Vertical Drain) into the slurry and then connecting them to the vacuum pump is a common practice [2]. However, poor performance has often been observed for vacuum treatment of the dredged slurry, e.g., the rates of the drainage flux, the settlement, and the pore water pressure dissipation drop significantly even at the early stage of the designed treatment period [3,4]. As a result, the improvements on the stiffness and the strength of the soil are too limited to satisfy requirements on the bearing capacity and post-construction settlement post by the infrastructures.

Recently, it was realized that the so-called soil column phenomenon was the main reason of the observed deficiency in vacuum treatment of the dredged slurry [5,6]. Different 
from the natural soil that is of stable soil skeleton, the dredged slurry is of extremely highwater content, and thus the fine particles in the slurry are generally in the suspended or loose-contacting status. Under the vacuum gradient, the slurry particles would migrate towards and then accumulate onto the PVD membrane, which forms the soil column with the PVD along its axis $[7,8]$. The soil column that is densely packed by the vacuum gradient is of extremely low permeability and thus impedes the drainage of the surrounding slurry [9].

With the realization of the physical importance of particle movements in explaining the inefficiency problem, both numerical and model-test studies have been carried out in the literature to characterize the particle motion and packing driven by the vacuum gradient in the slurry. Since the slurry contains both the solid and liquid phases, the current numerical studies generally adopt the two-phase approaches, e.g., the PFC software and the CFD-DEM method, in which the slurry particle is described by the DEM (Discrete Element Method) and the pore water is governed by the CFD (Computational Fluid Dynamics). The dynamic interactions between the particle and the fluid phases can be readily taken into account through the coupled CFD-DEM solver [10]. Based on the method, the problems of upward seepage [11], the soil consolidation [12], the underwater sedimentation [13], and the pipe erosion [14] can be modeled. Recently, a CFD-DEM-based model was established by Shi et al. [8] for reproducing the soil-column forming process under different vacuum pressures. Moreover, more refined models were built by Sun et al. [15] and Xu et al. [16] for investigating the jamming problem of the orifice of PVD membrane by the slurry particles. The CFD-DEM method is superior in explicitly resolving the motions of each slurry particle, which can help to understand the soil column phenomenon from a microscopic-scale view. However, the method may be subjected to severe limitations when it is used for modeling a real engineering-scale problem since enormous particles would be involved, and then the computational cost would be too high.

Alternatively, the model test is a generally accepted method for investigating problems of practical-engineering scale. Combined with the PIV (Particle Image Velocimetry) technology that is originally developed in the field of experimental fluid mechanics [17], the microscopic kinematic information of the particles can be obtained directly, which can serve as an important supplement to the commonly-observed macroscopic quantities. The PIV technique that can measure the displacement/velocity field of the soil particles has been widely used in geotechnical problems, such as the pile-soil interaction [18], the ground deformation induced by tunneling [19], the interaction of foundation structure and soil [20], etc. As for the vacuum consolidation of dredged slurry, the PIV analysis has been recently adopted by Pan et al. [21] and by Cai. [22] to obtain the displacement field of the slurry, based on which the formation mechanism of the soil column has been revealed.

As a non-intrusive testing method, the PIV technique fundamentally relies on the tracer particles to accomplish the image correlation analysis, i.e., the actual displacement/velocity field of the soil is represented by that of the tracer particles. However, the commonly-used and commercially available tracers, e.g., the carbon powder, could be of different diameters of mass density when compared to the measured objects, i.e., slurry particles in the present paper. Questions may arise over the representativeness of the tracers on the kinematic information of the slurry particles during the vacuum consolidation process, which is monitored by using the PIV technique.

To this aim, a microscopic model on vacuum consolidation of the slurry has been built using the CFD-DEM method. The slurry particles and the pore water are, respectively, described by the DEM and the CFD methods. Moreover, the PVD membrane is included in the model through fixed-in-space particles that are modeled by the DEM. The tracer particles that are also modeled by the DEM are distributed evenly over the slurry surface, which is the same as the tracer configuration in the practical PIV technique. By using the established model, the representativeness of the tracers on displacements of the slurry particles has been investigated for different combinations of the tracer diameter, the trace density, and the initial void ratio of the slurry soil. 


\section{Brief Introduction to CFD-DEM Solver}

The analysis involves a coupled CFD-DEM solver known as SediFoam (the source code is available at https:/ / github.com/xiaoh/sediFoam access date: 5 June 2017), which consists of three modules, i.e., the CFD module, the DEM module, and the coupled CFDDEM module. As shown in Figure 1, motions of the fluid and the particle are processed, respectively, in the CFD module and the DEM module. Their interactions are realized through the coupling module.

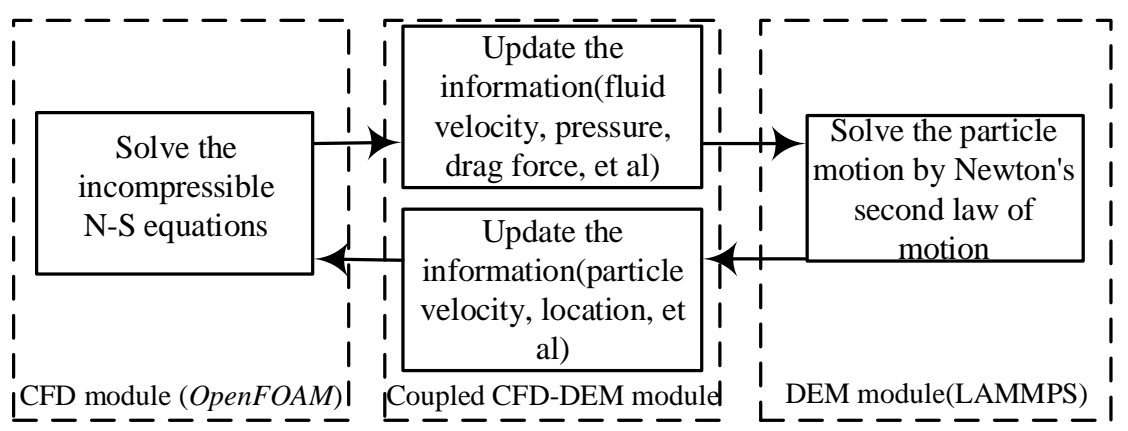

Figure 1. Flow path of SediFoam.

\subsection{The Governing Equation of CFD}

In the CFD module, the fluid motion is solved by the locally-averaged incompressible Navier-Stokes equations (N-S)

$$
\begin{gathered}
\nabla \cdot\left(\Phi_{s} \mathbf{U}_{s}+\Phi_{s} \mathbf{U}_{s}\right)=0 \\
\frac{\partial\left(\Phi_{f} \mathbf{U}_{f}\right)}{\partial t}+\nabla \cdot\left(\Phi_{f} \mathbf{U}_{f} \mathbf{U}_{f}\right)=\frac{1}{\rho_{f}}\left(-\nabla p+\Phi_{f} \nabla \cdot \tau+\Phi_{f} \rho_{f} \mathrm{~g}+\mathbf{f}^{f p}\right)
\end{gathered}
$$

where $\Phi_{s}$ and $\Phi_{f}$ are the solid and fluid volume fractions, respectively; $\mathbf{U}_{s}$ is the velocity of the particle; $\mathbf{U}_{f}$ is the fluid velocity; $\nabla p$ is the pressure gradient; $\nabla$ is the divergence operator; $\tau$ is the viscous stress tensor; $\rho_{f}$ is the density of fluid; $\mathbf{f}^{f p}$ is the volumetric interaction force acting on the fluid by the particles within each cell; $t$ denotes time; $g$ is the acceleration of gravity.

\subsection{The Governing Equation of DEM}

In the DEM module, based on Newton's second law, the particle motion is determined by solving the following equations

$$
\begin{gathered}
m \frac{\mathrm{d} \mathbf{U} s}{\mathrm{~d} t}=\mathbf{f}^{c o l}+\mathbf{f}^{\mathrm{f} p}+m \mathrm{~g} \\
I \frac{\mathrm{d} \varphi}{d t}=\mathbf{T}^{c o l}+\mathbf{T}^{f p}
\end{gathered}
$$

where $m$ is the mass of particle; $\mathbf{f}^{c o l}$ is the contact force between the particles or between the particle and the fixed boundary; $\mathbf{f}^{f p}$ is the fluid-particle interaction force (including the drag force, the lift force and the buoyancy force, etc.); I represents the angular moment of inertia of particles; $\varphi$ represents the angular velocity of particle; $\mathbf{T}^{c o l}$ and $\mathbf{T}^{f p}$ represent the torque due to the collision between particles and the particle-fluid interactions, respectively.

\section{Verification of the CFD-DEM Solver}

In this section, the coupled CFD-DEM solver Sedifoam presented in the above is used to simulate the settlement of spherical particles, providing the computational results to which the empirical solutions are compared and thus account for the validity of the coupled solver. 


\subsection{Richardson' Empirical Formula}

Based on a large number of experimental data analyses, a widely accepted empirical equation on particle sedimentation rate of uniformly sized spherical particles was proposed by Richardson et al. [23] as

$$
\log V_{(s, c)}=n \log c_{f}+\log V_{(s, 0)}=n \log 1-c_{s}+\log V_{(s, 0)}
$$

where $c_{f}$ is the volume fraction of the fluid; $c_{s}$ is the volume fraction of the solid; $V_{(s, c)}$ is the settling rate when the concentration of suspended particles is $c ; V_{(s, 0)}$ is the settlement rate of a single suspended particle; $n$ is the empirical parameter in different fluid states and expressed as below

$$
\begin{gathered}
n=4.65+19.5 \frac{d}{D} \quad(\operatorname{Re}<0.2) \\
n=\left(4.35+17.5 \frac{d}{D}\right) \operatorname{Re}^{-0.03}(0.2<\operatorname{Re}<1)
\end{gathered}
$$

where $d$ is the diameter of spherical particles and $D$ is the diameter of the model vessel; $R e$ is known as Reynolds number, and $v$ presents the dynamic viscosity of the fluid. Since the settling problem of soil particles in water is considered herein, only the equations corresponding to $R e<1$ need to be included, i.e., Equations (6) and (7).

\subsection{Numerical Model on Particle Sedimentation}

As illustrated in Figure 2, a three-dimensional numerical model incorporating the multiple spherical particles and the viscous fluid was established in the CFD-DEM solver SediFoam. The fluid and the particle were simulated by the CFD and the DEM, respectively. For the DEM discretization domain, the wall boundary conditions were adopted. While for the CFD discretization domain, the fluid velocity and pressure were set as zero and zerogradient on the top surface of the model, respectively, i.e., the patch boundary condition. Moreover, on the remaining boundary surfaces, the slip-wall and zero-gradient conditions were assigned to the fluid velocity and the pressure, respectively, i.e., the wall boundary condition. The length, width, and height of the numerical model were $0.01,0.01$, and $0.2 \mathrm{~m}$, respectively. The even-sized particles were of diameter $0.001 \mathrm{~m}$. Based on the initial concentration $c$ of particles, four cases were set up, which were Case $1(c=0)$, Case 2 $(c=0.05)$, Case $3(c=0.1)$, and Case $4(c=0.25)$. Parameters of the numerical model are summarized in Table 1.

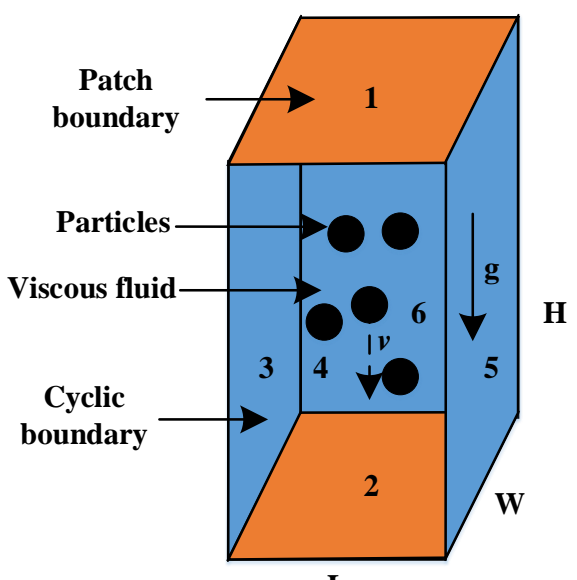

$\mathbf{L}$

Figure 2. Numerical model on settlement of multiple particles. 
Table 1. Parameters of sedimentation model of multiple particles.

\begin{tabular}{|c|c|c|c|c|c|}
\hline \multirow[t]{2}{*}{ Parameter } & \multirow[t]{2}{*}{ Symbol } & \multicolumn{4}{|c|}{ Value } \\
\hline & & Case1 & Case2 & Case3 & Case4 \\
\hline \multicolumn{6}{|c|}{ Particle-DEM } \\
\hline Number & $N$ & 1 & 955 & 1910 & 4775 \\
\hline Concentration & c & 0 & 0.05 & 0.1 & 0.25 \\
\hline Diameter/(m) & $d_{s}$ & 0.001 & 0.001 & 0.001 & 0.001 \\
\hline $\begin{array}{c}\text { Mass } \\
\text { density } /\left(\mathrm{kg} / \mathrm{m}^{3}\right)\end{array}$ & $\rho_{s}$ & 2650 & 2650 & 2650 & 2650 \\
\hline Stiffness/(N/m) & $k_{n} / k_{t}$ & $500 / 143$ & $500 / 143$ & $500 / 143$ & $500 / 143$ \\
\hline Damping/(N/ms) & $\gamma_{n} / \gamma_{t}$ & $20,000 / 10,000$ & $20,000 / 10,000$ & $20,000 / 10,000$ & $20,000 / 10,000$ \\
\hline Friction coefficient & $\mu$ & 0.4 & 0.4 & 0.4 & 0.4 \\
\hline \multicolumn{6}{|c|}{ Fluid-CFD } \\
\hline $\begin{array}{c}\text { Mass } \\
\text { density } /\left(\mathrm{kg} / \mathrm{m}^{3}\right)\end{array}$ & $\rho_{f}$ & \multicolumn{4}{|c|}{1000} \\
\hline Viscosity $/\left(\mathrm{m}^{2} / \mathrm{s}\right)$ & $v$ & \multicolumn{4}{|c|}{$10^{-6}$} \\
\hline Gravity $\left(\mathrm{m} / \mathrm{s}^{2}\right)$ & $g$ & \multicolumn{4}{|c|}{9.8} \\
\hline \multicolumn{6}{|c|}{ Domain dimensions } \\
\hline Length/(m) & $L$ & \multicolumn{4}{|c|}{0.01} \\
\hline Wide/(m) & $W$ & \multicolumn{4}{|c|}{0.01} \\
\hline Height/(m) & $H$ & \multicolumn{4}{|c|}{0.2} \\
\hline Mesh size/(m) & & \multicolumn{4}{|c|}{$0.002 \times 0.002 \times 0.002$} \\
\hline
\end{tabular}

By substituting the settlement rate of a single suspended particle $V_{(s, 0)}=0.141 \mathrm{~m} / \mathrm{s}$ and the diameter of the model vessel $D=0.02 \mathrm{~m}$ into Equation (1), the predictions of the Richardson empirical formula on various particle concentrations are presented in Table 2.

Table 2. Predictions of the Richardson empirical formula.

\begin{tabular}{|c|c|c|c|c|c|c|c|c|c|c|}
\hline Parameter & Symbol & & & & & Value & & & & \\
\hline Diameter /(m) & $D$ & & & & & 0.02 & & & & \\
\hline Particle size/(m) & $d$ & & & & & 0.001 & & & & \\
\hline Reynolds number & $\operatorname{Re}$ & & & & & 141 & & & & \\
\hline Empirical coefficient & $n$ & & & & & 3.8103 & & & & \\
\hline Particle concentration & $c$ & 0 & 0.05 & 0.10 & 0.25 & 0.50 & 0.75 & 0.90 & 0.95 & 1.00 \\
\hline Velocity/(m/s) & $V_{(s, c)}$ & 0.141 & 0.116 & 0.0944 & 0.0471 & 0.0101 & 0.000717 & 0.0000218 & 0.00000156 & 0 \\
\hline
\end{tabular}

Figure 3 illustrates that the velocity of uniformly sized spherical particles varies the particle concentration during the settlement process. The simulated values agree well with the predictions of the empirical formula, which verifies the correctness of the CFD-DEM solver Sedifoam. 


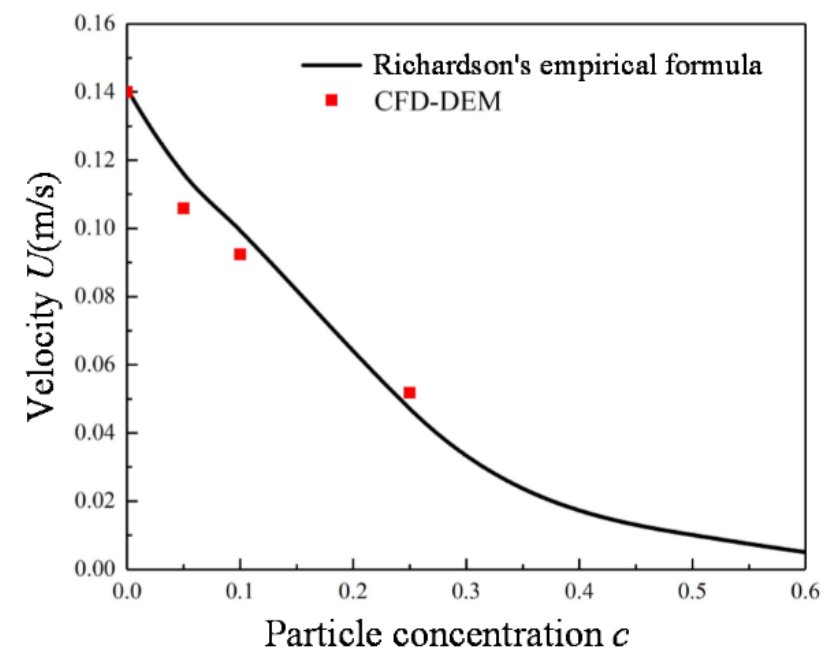

Figure 3. Variation of settling velocity of a uniformly sized spherical particle with the particle concentration.

\section{Numerical Model}

The PIV model test on vacuum consolidation of dredged slurry involves interactions between the PIV tracers, the slurry particles, the pore water, and the PVD membrane. Successful modeling requires proper considerations on numerical representations of the involving parts.

\subsection{Modeling on PVD Membrane}

The vital function of PVD is the drainage capacity, which is controlled by membrane apertures $[24,25]$. The membraned aperture involved in the industry is quantitatively described by the pore-opening size $O_{95}$, which corresponds to $5 \%$ sieving rate of particles. Index properties of industrial PVD are summarized in Table 3.

Table 3. Index properties of PVD.

\begin{tabular}{|c|c|c|c|c|c|}
\hline Parameter & Type A & Type B & Type C & Type D & Test Condition \\
\hline Installation depth/(m) & $\leq 15$ & $\leq 25$ & $\leq 35$ & $\leq 50$ & \\
\hline Drainage capacity/(1000 $\left.\mathrm{mm}^{3} / \mathrm{s}\right)$ & $\geq 15$ & $\geq 25$ & $\geq 40$ & $\geq 55$ & Lateral pressure $350 \mathrm{kPa}$ \\
\hline $\begin{array}{l}\text { Permeability coefficient of } \\
\text { membrane } /(10 \mathrm{~mm} / \mathrm{s})\end{array}$ & \multicolumn{4}{|c|}{$\geq 5 \times 10^{-4}$} & Immersed in water for $24 \mathrm{~h}$ \\
\hline $\begin{array}{l}\text { Equivalent aperture diameter of } \\
\text { membrane } /(\mathrm{mm})\end{array}$ & \multicolumn{4}{|c|}{$<0.075$} & $\mathrm{O}_{95}$ \\
\hline $\begin{array}{l}\text { Tensile strength of PVD/ } \\
(\mathrm{kN} / 100 \mathrm{~mm})\end{array}$ & $\geq 1.0$ & $\geq 1.3$ & $\geq 1.5$ & $\geq 1.8$ & Elongation reached $10 \%$ \\
\hline \multirow{2}{*}{$\begin{array}{l}\text { Tensile strength of } \\
\text { membrane/(N/10 mm) }\end{array}$} & Dry state & $\geq 15$ & $\geq 25$ & $\geq 30$ & Elongation reached $10 \%$ \\
\hline & Wet state & $\geq 10$ & $\geq 20$ & $\geq 25$ & $\begin{array}{l}\text { Immersed in water for } 24 \mathrm{~h} \\
\text { when elongation reached } 10 \%\end{array}$ \\
\hline
\end{tabular}

According to the manufacturing process [26], the PVD membrane can presently be divided into the non-woven fabric and woven fabric. The former is obtained by the fusion of fiber molecules in random directions; while, the latter turns the fiber into yarn and interweaves in the orthogonal direction. In order to alleviate the complexity of modeling, only the woven fabric structure was taken into account, as shown in Figure 4. The PVD membrane was established numerically by rectangular arrangements of spherical particles that were uniform in size, as shown in Figure 5. There were 336 spherical particles of diameter $5 \mu \mathrm{m}$ being used in establishing the membrane model, of which the dimensions were $100 \mu \mathrm{m}$ (length) $\times 100 \mu \mathrm{m}$ (width) $\times 5 \mu \mathrm{m}$ (thickness). The particle packs represent 
the membrane fibers that were evenly spaced along both directions of the membrane plane. As compared in Figure 4, the present numerical model of membrane properly represents the actual fabric structure of the woven PVD membrane. The resulting openings bounded by the fibers were of a rectangular size, of which the equivalent diameter $D$ was set to $O_{95}$ of the PVD membrane prototype, i.e., $D=O_{95}=20 \mu \mathrm{m}$. Thus, the pore-opening size of the membrane model satisfies the corresponding industrial requirement in Table 3, i.e., $O_{95}=20 \mu \mathrm{m}<75 \mu \mathrm{m}$. It is noteworthy that this structure not only controls the equivalent pore-opening size, but also contributes to the permeability coefficient of the membrane. Moreover, the permeability coefficient, calculated by the coupled CFD-DEM solver, is $k=4.35 \times 10^{-4} \mathrm{~m} / \mathrm{s}$, which meets the industrial manufacturing requirements of PVD membrane in Table 3, i.e., $k \geq 5 \times 10^{-5} \mathrm{~m} / \mathrm{s}$.

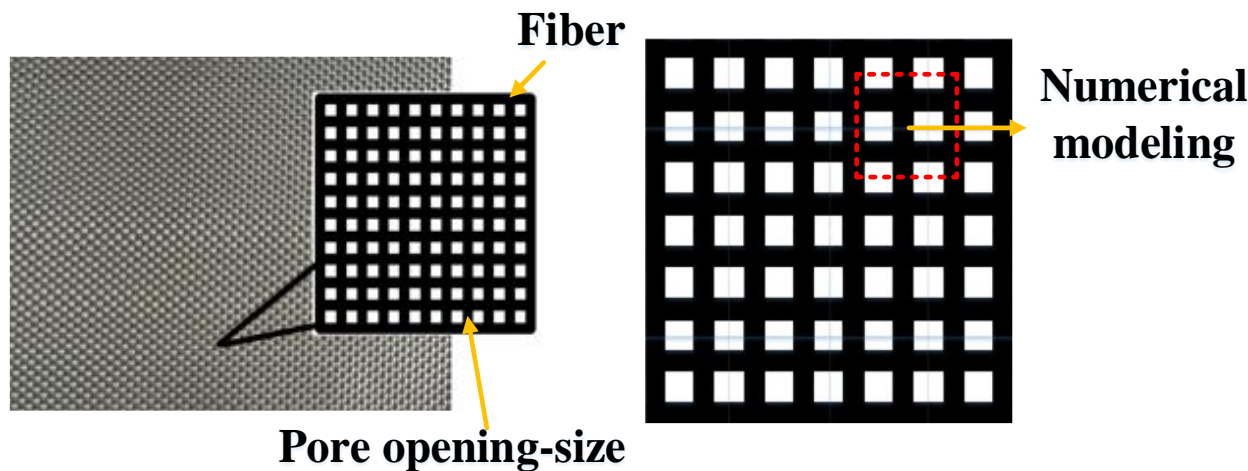

Figure 4. Structure of a PVD membrane of woven fabric.

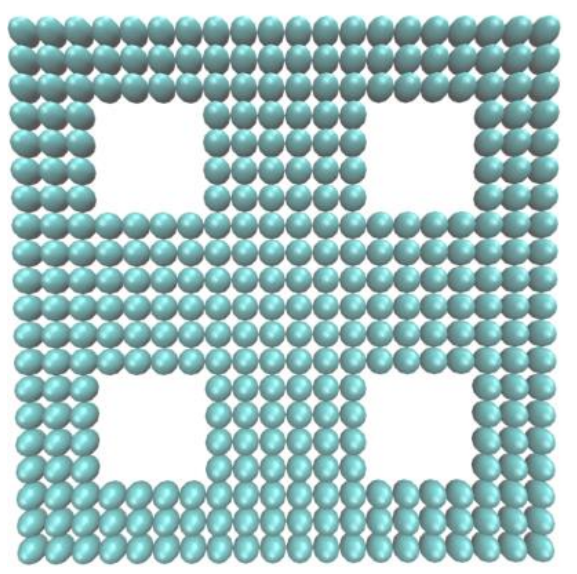

(a)

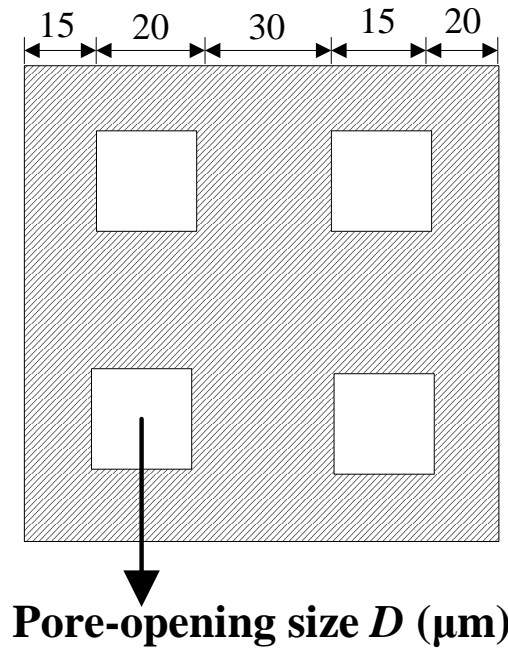

(b)

Figure 5. Numerical modeling on PVD membrane: (a) DEM modeling on PVD membrane, (b) schematic plan view on the membrane.

\subsection{Modeling on Slurry and PIV Tracers}

By using the CFD-DEM solver SediFoam, the particles of the slurry and the tracers used in the PIV test were described by DEM, while the pore water was governed by the CFD method. The three-dimensional model incorporating the slurry, the tracers, and the PVD membrane is shown in Figure 6a tighter with illustrations on the model structure given in Figure $6 \mathrm{~b}$. The model was of cuboid shape with a height of $400 \mu \mathrm{m}$ and square bottom of side length of $100 \mu \mathrm{m}$. As shown in Figure 6b, along the model height, the computational domain can be functionally divided into three regions, i.e., the particle-fluid mixed region ranging from 100 to $400 \mu \mathrm{m}$, the membrane region ranging from 95 to $100 \mu \mathrm{m}$ and the pure water region ranging from 0 to $95 \mu \mathrm{m}$. 


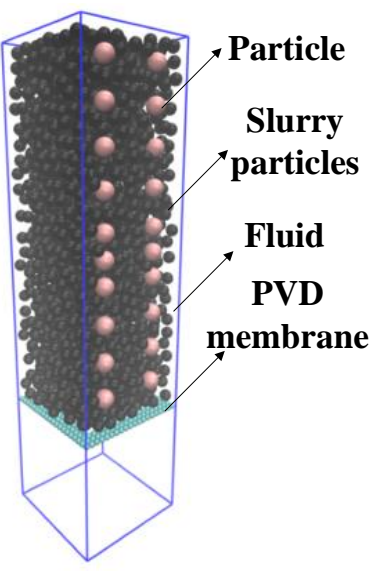

(a)

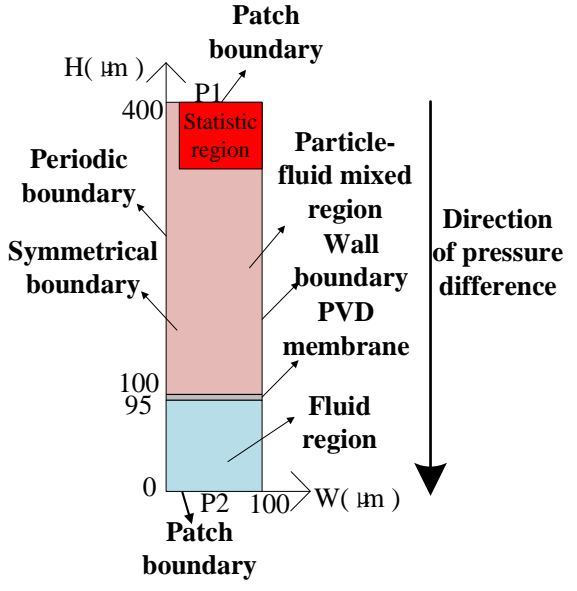

(b)

Figure 6. Diagram of the numerical model: (a) three-dimensional model, (b) model structure.

In order to save computational cost as well as to simplify the calculation of particle interaction forces, the slurry particles were idealized into spheres, which were randomly scattered in the mixed region and not allowed to overlap with each other, as shown in Figure 6a. The number of the spheres was determined according to the initial void ratio of the slurry. The tracers were also modeled as spheres. However, they were evenly scattered only to the right boundary region of the model, as shown in Figure 6a, which was different from the slurry particles that were randomly distributed within the entire computational domain. Those tracer particles were tangential to the right boundary of the model, which mimics the situation that the tracer particles were scattered onto the inside surface of the observation window in the actual PIV test. As for the membrane, the constituting particles were fixed in space throughout the simulation. The pure water region merely serves to provide extra space for the continuous movement of particles that have passed through the membrane.

The particle size distribution of the actual slurry that was sampled from Wenzhou of eastern China is shown in Figure 7. It was observed that the particle size generally confines to the range of $2 \sim 50 \mu \mathrm{m}$ with the median size $d_{50} \approx 20 \mu \mathrm{m}$. To make a reasonable representation of the actual slurry and also to reasonably simplify the modeling work, uniformly-sized spherical particles of diameter $d=10 \mu \mathrm{m}$ were adopted here to model the slurry. It was noted that $d=10 \mu \mathrm{m}$ was less than $D=20 \mu \mathrm{m}$, which means the slurry particles were able to pass the membrane. Two concentrations of slurry particles that can be equivalently expressed as the initial void ratio $e_{0}=2$ and 3 were considered for the slurry.

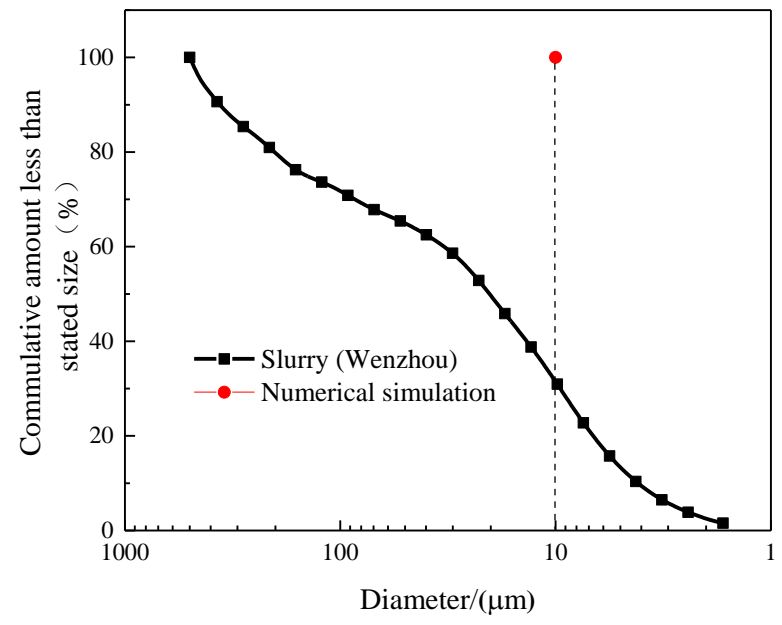

Figure 7. Particle size distribution of dredged slurry sampled from Wenzhou. 
One of the commonly used tracers is dark carbon powder that has a minimum diameter of about $16 \mu \mathrm{m}$. Correspondingly, tracers of three diameters were considered in the model, i.e., $d_{\mathrm{t}}=16,18$, and $25 \mu \mathrm{m}$. Additionally, two mass densities $\rho_{\mathrm{t}}=2000$ and $2650 \mathrm{~kg} / \mathrm{m}^{3}$ were specified for the tracer to consider the tracers of different material origin, e.g., carbon powders and sand grains. Under the different combinations of the initial void ratio $e_{0}$ of the slurry, the diameter $d_{\mathrm{t}}$ and the mass density $\rho_{\mathrm{t}}$ of the tracer, 8 modeling cases were considered in the present paper, which is summarized in Table 4, together with the geometry and material parameters of the solid and fluid phases. The different cases can cover a wide spectrum of the PIV model tests on the dredged slurry.

Table 4. Modeling cases and parameters of dredged slurry and PIV tracers.

\begin{tabular}{|c|c|c|c|c|c|c|c|c|c|}
\hline Parameter & Symbol & \multicolumn{8}{|c|}{ Value } \\
\hline \multicolumn{10}{|c|}{ Particle_PVD membrane } \\
\hline Number & & \multicolumn{8}{|c|}{336} \\
\hline Diameter /(m) & $d$ & \multicolumn{8}{|c|}{$5 \times 10^{-6}$} \\
\hline $\begin{array}{l}\text { Density } \\
/\left(\mathrm{kg} / \mathrm{m}^{3}\right)\end{array}$ & $\rho$ & \multicolumn{8}{|c|}{500} \\
\hline \multicolumn{10}{|c|}{ Particle-Slurry particle } \\
\hline & & Case1 & Case2 & Case3 & Case4 & Case5 & Case6 & Case7 & Case8 \\
\hline Number & & 1751 & 1340 & 1400 & 1776 & 1751 & 1340 & 1400 & 1776 \\
\hline Diameter /(m) & $d_{\mathrm{s}}$ & \multicolumn{8}{|c|}{$1.0 \times 10^{-5}$} \\
\hline $\begin{array}{l}\text { Density } \\
/\left(\mathrm{kg} / \mathrm{m}^{3}\right)\end{array}$ & $\rho_{\mathrm{s}}$ & \multicolumn{8}{|c|}{2650} \\
\hline Void ratio & $e_{0}$ & 3 & 3 & 3 & 2 & 3 & 3 & 3 & 2 \\
\hline $\begin{array}{c}\text { Slurry } \\
\text { Thickness/(m) }\end{array}$ & $h$ & $3 \times 10^{-4}$ & $3 \times 10^{-4}$ & $3 \times 10^{-4}$ & $3 \times 10^{-4}$ & $3 \times 10^{-4}$ & $3 \times 10^{-4}$ & $3 \times 10^{-4}$ & $3 \times 10^{-4}$ \\
\hline \multicolumn{10}{|c|}{ Particle-Tracer particle } \\
\hline Number & & 20 & 12 & 5 & 12 & 20 & 12 & 5 & 12 \\
\hline Diameter /(m) & $d_{\mathrm{s}}$ & 16 & 18 & 25 & 18 & 16 & 18 & 25 & 18 \\
\hline $\begin{array}{c}\text { Density } \\
/\left(\mathrm{kg} / \mathrm{m}^{3}\right)\end{array}$ & $\rho_{\mathrm{s}}$ & 2650 & 2650 & 2650 & 2650 & 2000 & 2000 & 2000 & 2000 \\
\hline \multicolumn{10}{|c|}{ Particle-DEM } \\
\hline $\begin{array}{l}\text { Stiffness } \\
/(\mathrm{N} / \mathrm{m})\end{array}$ & $k_{n} / k_{t}$ & \multicolumn{8}{|c|}{$500 / 143$} \\
\hline Damping/(N/ms) & $\gamma_{n} / \gamma_{t}$ & \multicolumn{8}{|c|}{$20,000 / 10,000$} \\
\hline $\begin{array}{l}\text { Friction } \\
\text { coefficient }\end{array}$ & $\mu$ & \multicolumn{8}{|c|}{0.4} \\
\hline \multicolumn{10}{|c|}{ Fluid-CFD } \\
\hline Density/(kg/m³) & $\rho_{f}$ & \multicolumn{8}{|c|}{1000} \\
\hline Viscosity $/\left(\mathrm{m}^{2} / \mathrm{s}\right)$ & $v$ & \multicolumn{8}{|c|}{$1.0 \times 10^{-6}$} \\
\hline Gravity $/\left(\mathrm{m} / \mathrm{s}^{2}\right)$ & $\mathrm{g}$ & \multicolumn{8}{|c|}{9.8} \\
\hline \multicolumn{10}{|c|}{ Domain dimensions } \\
\hline Height/(m) & $H$ & \multicolumn{8}{|c|}{$4 \times 10^{-4}$} \\
\hline Width/(m) & $W$ & \multicolumn{8}{|c|}{$1 \times 10^{-4}$} \\
\hline Length/(m) & $L$ & \multicolumn{8}{|c|}{$1 \times 10^{-4}$} \\
\hline
\end{tabular}

\subsection{Boundary Conditions}

The wall boundary conditions were adopted for the DEM domain. As for the CFD domain, on the top and the bottom surfaces of the model, the zero-gradient and the fixedvalue boundary conditions, i.e., the patch boundary condition, were assigned to the fluid velocity and the pressure, respectively; on the front and back surfaces, the symmetrical boundary conditions were prescribed; for the right side surface that was tangential to the 
tracers, the wall boundary condition was applied; and for the left side surface, the periodic boundary condition was specified. The above boundary conditions have been indicated in Figure $6 \mathrm{~b}$.

In the engineering practice, the designed value of vacuum pressure $P$ was generally $80 \mathrm{kPa}$, and the spacing $s$ between PVDs was about $1.4 \mathrm{~m}$. Then the maximum pressure gradient across the slurry can be estimated as $i=P /(s / 2)=114 \mathrm{kPa} / \mathrm{m}$. However, the actual pressure gradient is usually smaller than $114 \mathrm{kPa} / \mathrm{m}$ since the vacuum pressure at soil increases along with the consolidation process. In the numerical model, the thickness of the slurry and the pressure difference was set to $0.3 \mathrm{~mm}$ and $30 \mathrm{~Pa}$, respectively. Then, the corresponding pressure gradient was $100 \mathrm{kPa} / \mathrm{m}$, which was close to $i=114 \mathrm{kPa} / \mathrm{m}$ in practice. The pressure gradient was achieved by setting zero $\left(P_{\mathrm{a}}=0 \mathrm{~Pa}\right)$ and negative pressures $\left(P_{\mathrm{b}}=-30 \mathrm{~Pa}\right)$ to the top and bottom surfaces of the CFD domain, respectively.

\section{Numerical Results}

The slurry particles and the tracers move together toward the drainage board filter membrane under the vacuum gradient. However, their displacements should not be the same due to the differences in physical properties such as particle size and density. As shown in Table 4, eight cases considering different combinations of the tracer density $\left(\rho_{\mathrm{t}}\right)$, tracer size $\left(d_{\mathrm{t}}\right)$, and initial void ratio $\left(e_{0}\right)$ of the dredged slurry. As shown in Figure $6 \mathrm{~b}, \mathrm{a}$ statistical region of $25 \times 100 \times 85 \mu \mathrm{m}$ in length $\times$ width $\times$ height was defined within the particle-fluid mixed region. The particles in the statistical region were sufficiently away from the PVD membrane and thus had large space for movement, which was beneficial to obtaining more particle movement information.

Figure 8 compares the time variation of the ratio $\left(D_{\mathrm{t}} / D_{\mathrm{s}}\right)$ between the statistical displacements of the tracers $D_{\mathrm{t}}$ and the slurry particles $D_{\mathrm{s}}$ for three cases of $d_{\mathrm{t}} / d_{s}=1.6,1.8$, and 2.5 , i.e., Cases $1 \sim 3$ in Table 4 . The mass density of the tracer and the initial void ratio of the slurry were taken as $\rho_{\mathrm{t}}=2650 \mathrm{~kg} / \mathrm{m}^{3}$ and $e_{0}=3$, respectively. Obviously, better representativeness of the tracer for the slurry particles can be achieved when $D_{\mathrm{t}} / D_{\mathrm{s}}$ is closer to 1 . It can be seen from the figure that $D_{\mathrm{t}} / D_{\mathrm{s}}$ tends to be stable after the previous fluctuations. The stable values of $D_{\mathrm{t}} / D_{\mathrm{s}}$ in Cases 1 3 were 1.042, 1.089, and 1.137, respectively. The observations indicate that the representativeness of the tracer decreases when the diameter ratio between the tracer and the slurry particle $\left(d_{\mathrm{t}} / d_{\mathrm{s}}\right)$ increases.

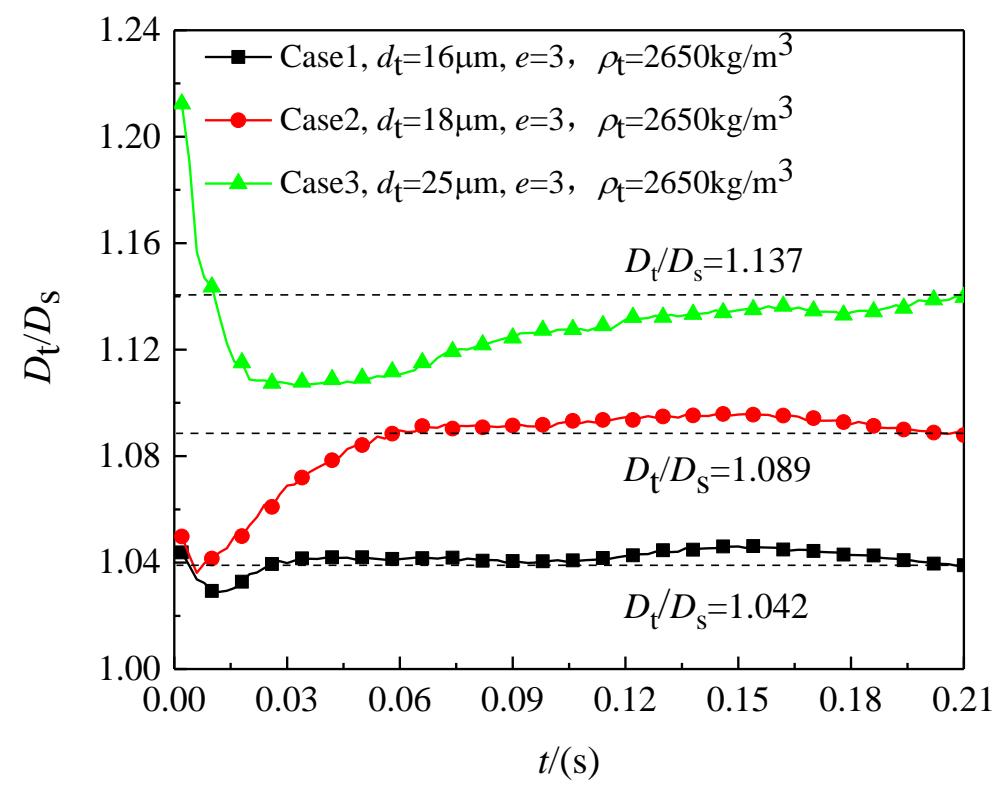

Figure 8. Variations of displacement ratio $D_{\mathrm{t}} / D_{\mathrm{s}}$ between tracer and slurry particle with respect to time $\mathrm{t}$ under conditions of $\rho_{\mathrm{t}}=2650 \mathrm{~kg} / \mathrm{m}^{3}, e_{0}=3$ and $d_{\mathrm{t}} / d_{\mathrm{s}}=1.6,1.8$ and 2.5 . 
By reducing the mass density $\rho_{\mathrm{t}}$ of the tracer from $2650 \mathrm{~kg} / \mathrm{m}^{3}$ to $2000 \mathrm{~kg} / \mathrm{m}^{3}$ and keeping $e_{0}=3$, Figure 9 compares the variation of $D_{\mathrm{t}} / D_{\mathrm{s}}$ with $t$ for the same diameter ratios $d_{\mathrm{t}} / d_{\mathrm{s}}=1.6,1.8$, and 2.5 (i.e., Cases $5 \sim 7$ in Table 4). By comparing Figure 9 to Figure 8, it can be seen that the mass density of the tracer had little effect on the variation of $D_{\mathrm{t}} / D_{\mathrm{s}}$ with time. However, the stable values of $D_{\mathrm{t}} / D_{\mathrm{s}}$ were reduced, i.e., the reductions were about $1.4 \%, 3.5 \%$, and $10 \%$, respectively, for $d_{\mathrm{t}} / d_{\mathrm{s}}=1.6,1.8$, and 2.5 .

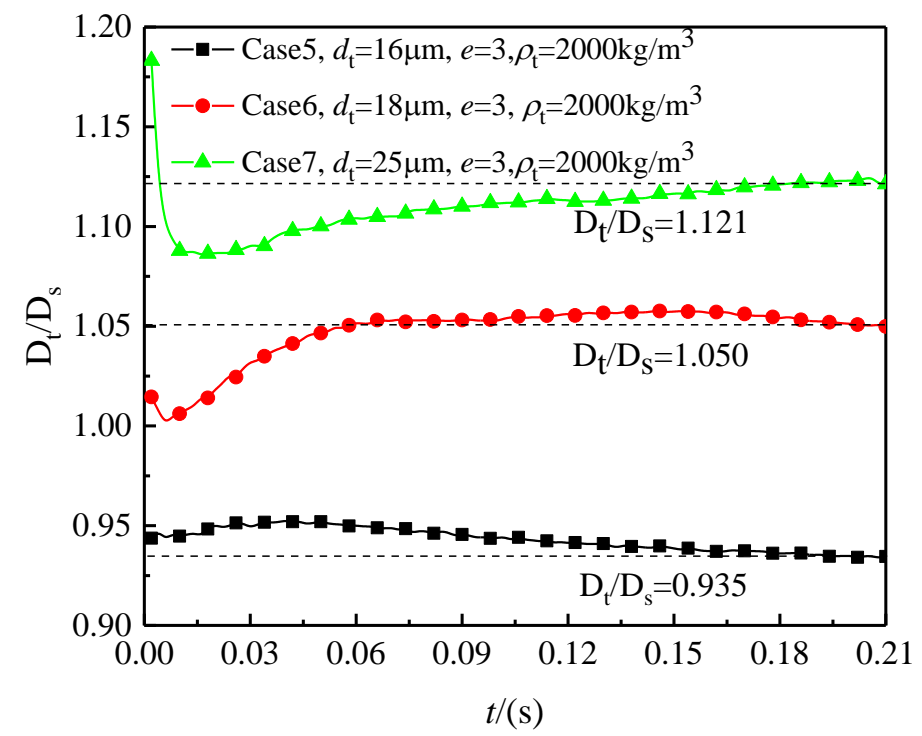

Figure 9. Variations of displacement ratio $D_{\mathrm{t}} / D_{\mathrm{s}}$ between tracer and slurry particle with respect to time $\mathrm{t}$ under conditions of $\rho_{\mathrm{t}}=2000 \mathrm{~kg} / \mathrm{m}^{3}, e_{0}=3, d_{\mathrm{t}} / d_{\mathrm{s}}=1.6,1.8$, and 2.5 .

Figure 10 summarizes the variations of the stable values of $D_{\mathrm{t}} / D_{\mathrm{s}}$ with $d_{\mathrm{t}} / d_{\mathrm{s}}$ for the two mass densities of the tracer, i.e., $\rho_{\mathrm{t}}=2650 \mathrm{~kg} / \mathrm{m}^{3}$ and $2000 \mathrm{~kg} / \mathrm{m}^{3}$. It can be seen from the figure that the stable value of $D_{t} / D_{s}$ increased with the mass density ratio $\rho_{t} / \rho_{\mathrm{s}}$, which means the representativeness of the tracer decreased. Among the Cases 1 3 and $5 \sim 7$ considered in Figure 10, the tracer of diameter $18 \mu \mathrm{m}$ and of mass density $2000 \mathrm{~kg} / \mathrm{m}^{3}$, i.e., Case 6, provided the best representativeness on the displacement response of the slurry particles.

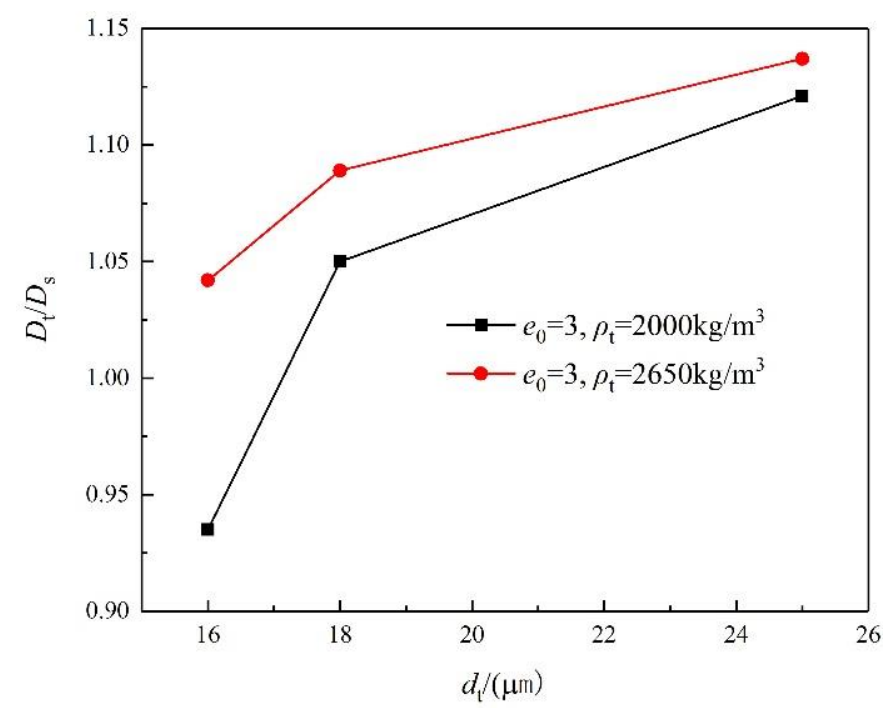

Figure 10. Variations of stable values of the displacement ratio $D_{t} / D_{s}$ with respect to the tracer diameter $\mathrm{dt}$ for two mass densities of the tracer, $\rho_{\mathrm{t}}=2000 \mathrm{~kg} / \mathrm{m}^{3}$ and $2650 \mathrm{~kg} / \mathrm{m}^{3}$. 
For slurries of different particle concentrations, the variations of $D_{\mathrm{t}} / D_{\mathrm{s}}$ with $t$ were compared in Figure 11a for two initial void ratios, i.e., $e_{0}=2$ and 3. In producing Figure 11a, the diameter and mass density of the tracer were, respectively, taken as $d_{\mathrm{t}}=18 \mu \mathrm{m}$ and $\rho_{\mathrm{t}}=2650 \mathrm{~kg} / \mathrm{m}^{3}$, i.e., Cases 2 and 4 . By changing $\rho_{\mathrm{t}}=2650 \mathrm{~kg} / \mathrm{m}^{3}$ to $2000 \mathrm{~kg} / \mathrm{m}^{3}$, the Cases 2 and 4 become Cases 6 and 8, for which the corresponding results are presented in Figure 11b. For both considerations on the mass densities, it was seen that the stable values of $D_{\mathrm{t}} / D_{\mathrm{s}}$ increased with $e_{0}$, which means the representativeness of the tracer became worse for slurries of higher initial void ratio. Comparing Figure 11a,b, it can also be found that the representativeness of the tracer increased when the density of the tracer decreased. For all of the eight cases considered in Table 4, Case 8 gives the best representativeness on the displacements of the slurry particles that were driven by the vacuum gradient.

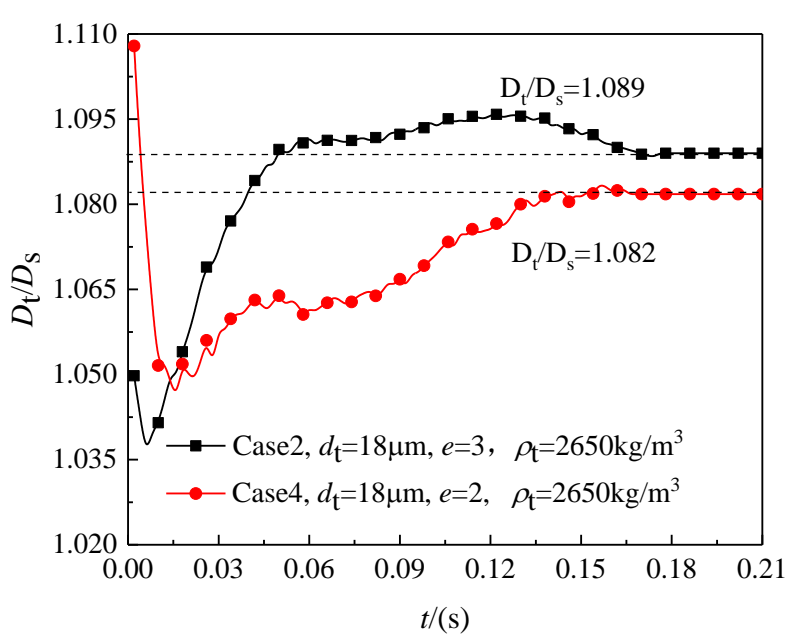

(a)

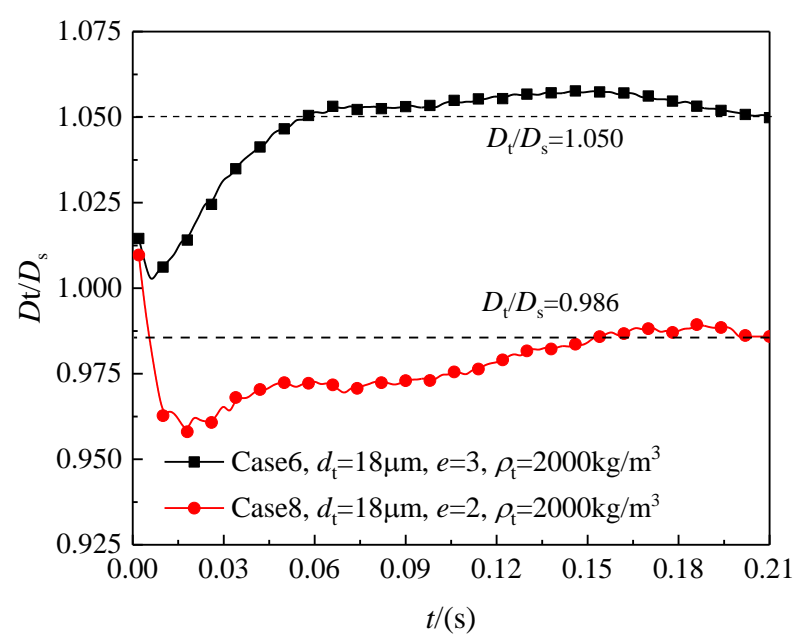

(b)

Figure 11. Variations of displacement ratio $D_{\mathrm{t}} / D_{\mathrm{s}}$ between tracer and slurry particle with respect to time $t$ under conditions of $e_{0}=2,3$ and $d_{\mathrm{t}}=18 \mu \mathrm{m}:(\mathbf{a}) \rho_{\mathrm{t}}=2650 \mathrm{~kg} / \mathrm{m}^{3} ;$ (b) $\rho_{\mathrm{t}}=2000 \mathrm{~kg} / \mathrm{m}^{3}$.

\section{Discussions}

From the eight cases in Table 4 that cover the common ranges of material parameters governing the PIV model tests on the dredged slurry, the stable displacement ratio $\left(D_{\mathrm{t}} / D_{\mathrm{s}}\right)$ between the tracer and the slurry particle varies between 0.935 and 1.137. The representativeness of the tracer is acceptable if compared to the ideal value $D_{\mathrm{t}} / D_{\mathrm{s}}=1$, i.e., the largest difference is about $14 \%$. Particularly for the commonly used tracers, the carbon powder of mass density $2000 \mathrm{~kg} / \mathrm{m}^{3}$, it is observed from Cases $5 \sim 8$ that $D_{\mathrm{t}} / D_{\mathrm{s}}$ varies in the range of $0.935 \sim 1.05$ if the carbon powder is of diameter ratio $d_{\mathrm{t}} / d_{\mathrm{s}}$ within 1.8. The largest difference is only about $6.5 \%$, which means the motions of the slurry particles can be reliably represented by the carbon powders. It is suggested that for the slurry of high-water content, the carbon powder of diameter close to the median size of the slurry particles should be used. Moreover, for a slurry of higher particle concentration, i.e., lower water content, the size of the carbon powder can be slightly increased to facilitate the observations of the PIV camera.

\section{Conclusions}

In this paper, a mesoscopic model has been established by using coupled CFD-DEM solver SediFoam to reproduce the vacuum consolidation process of the slurry, in which the PVD (Prefabricated Vertical Drain) membrane, the slurry particles, and the tracers are described by the DEM, and the pore water is governed by the CFD method. Eight computational cases that cover a broad range of material parameters governing the PIV model tests on vacuum consolidation of the dredged slurry have been designed and investigated by the established CFD-DEM model. The representativeness of the PIV tracer 
is evaluated by comparing the statistic displacement of the tracer to that of the slurry particles. The following conclusions can be drawn:

(1) For tracers that are made by carbon powders of mass density $2000 \mathrm{~kg} / \mathrm{m}^{3}$ or by sand grains of mass density $2650 \mathrm{~kg} / \mathrm{m}^{3}$, the stable displacement ratio $\left(D_{\mathrm{t}} / D_{\mathrm{s}}\right)$ between the tracer and the slurry particle varies between 0.935 and 1.137 if the tracer/slurry particle diameter ratio $d_{\mathrm{t}} / d_{\mathrm{s}}$ and the initial void ratio $e_{0}$ of the slurry varies in the ranges of 1.6 2.5 and 2 3, respectively. Thus, the representativeness of the tracer is acceptable if compared to the ideal value $D_{\mathrm{t}} / D_{\mathrm{s}}=1$, since the largest difference is about $14 \%$.

(2) For tracers made by the carbon powders of diameter within 1.8 times the median size of the slurry particles, the representativeness of the PIV tracers can be significantly improved since the displacement ratio $D_{\mathrm{t}} / D_{\mathrm{s}}$ varies in the small range of $0.935 \sim 1.05$, i.e., the largest difference is only about $6.5 \%$.

(3) Generally speaking, the representatives of the PIV tracers on the displacements of the slurry particles can be improved for tracers of $d_{\mathrm{t}} / d_{\mathrm{s}}$ closer to 1 and for slurries of lower initial water content, i.e., lower initial void ratio $e_{0}$.

Author Contributions: Conceptualization, L.S. and Z.F.; methodology Y.Y., J.W. and L.S.; software, G.W.; validation, Z.F., Y.Y. and G.W.; formal analysis L.S.; writing-original draft preparation, Z.F.; writing-review and editing, L.S., Z.Y., K.Y. and J.H. All authors have read and agreed to the published version of the manuscript.

Funding: This research was funded by the Natural and Science Foundation of China, grant number 51879234.

Conflicts of Interest: The authors declare no conflict of interest.

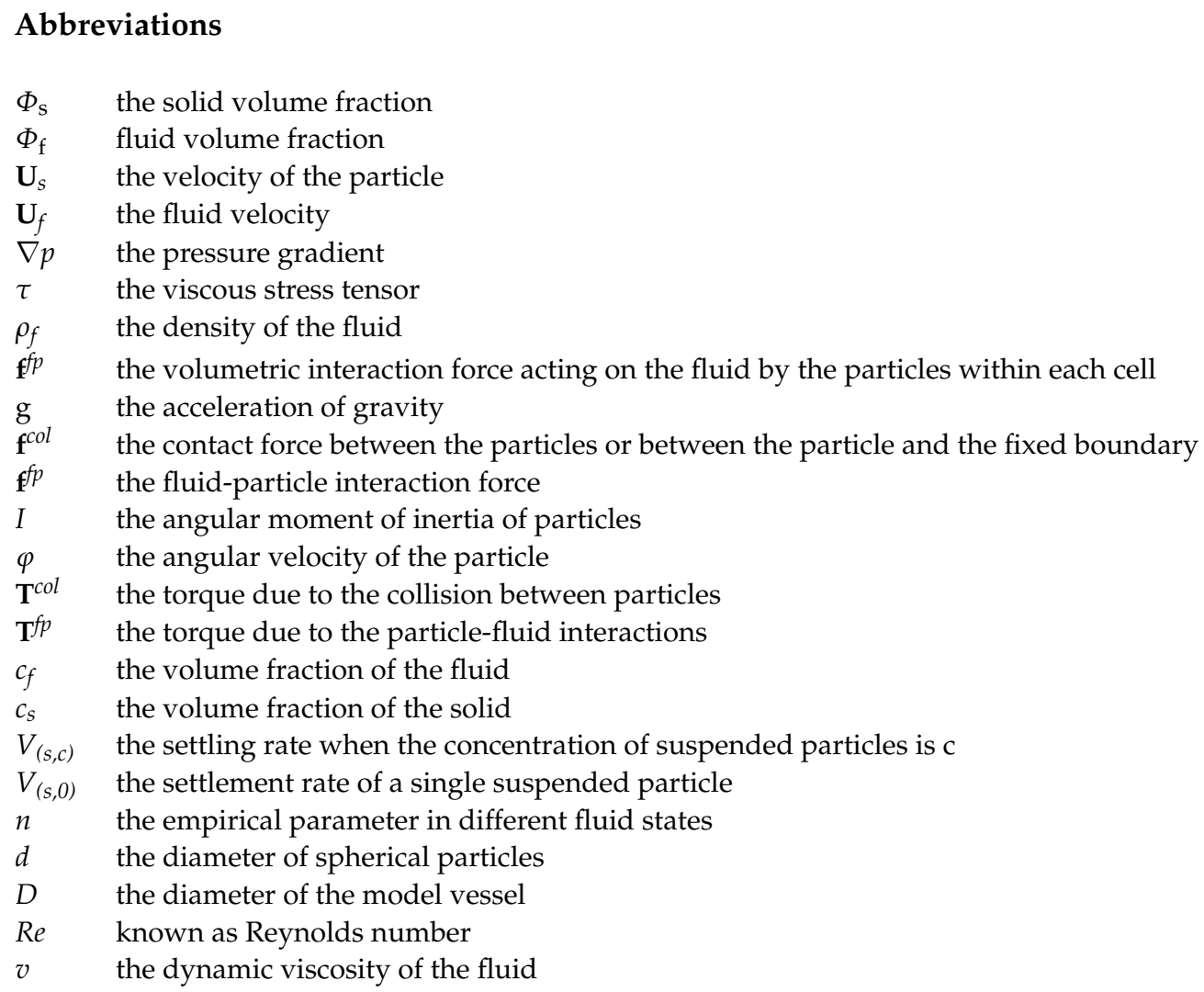




\section{References}

1. Chu, J.; Yan, S.; Yang, H. Soil improvement by the vacuum preloading method for an oil storage station. Géotechnique 2000, 50, 625-632. [CrossRef]

2. Indraratna, B.; Bamunawita, C.; Khabbaz, H. Numerical modeling of vacuum preloading and field applications. Can. Geotech. J. 2004, 41, 1098-1110. [CrossRef]

3. Cai, Y.; Xie, Z.; Wang, J.; Wang, P.; Geng, X. New approach of vacuum preloading with booster prefabricated vertical drains (PVDs) to improve deep marine clay strata. Can. Geotech. J. 2018, 55, 1359-1371. [CrossRef]

4. Wang, J.; Ni, J.; Cai, Y. Combination of vacuum preloading and lime treatment for improvement of dredged fill. Eng. Geol. 2017, 227, 149-158. [CrossRef]

5. Lei, H.; Hu, Y.; Zheng, G.; Liu, J.; Wang, L.; Liu, Y. Improved air-booster vacuum preloading method for newly dredged fills: Laboratory model study. Mar. Georesour. Geotechnol. 2020, 38, 493-510. [CrossRef]

6. Cai, Y.; Qiao, H.; Wang, J.; Geng, X.; Wang, P. Experimental tests on effect of deformed prefabricated vertical drains in dredged soil on consolidation via vacuum preloading. Eng. Geol. 2017, 222, 10-19. [CrossRef]

7. He, N.; Cui, Y.; Liu, L.; Chen, X.; Feng, Q.; Deng, Y. Colloid effect on clogging mechanism of hydraulic reclamation mud improved by vacuum preloading. Can. Geotech. J. 2019, 56, 611-620.

8. Shi, L.; Wang, Q.; Xu, S.; Pan, X.; Sun, H.; Cai, Y. Numerical study on clogging of prefabricated vertical drain in slurry under vacuum loading. Granul. Matter 2018, 10, 20-74. [CrossRef]

9. Cai, Y.; Zhou, Y.; Wang, P.; Shi, L.; Wang, J. Calculation on settlement of dredged slurry treated by vacuum preloading method with consideration. Rock Soil Mech. 2020, 11, 1-10.

10. Sun, R.; Xiao, H. SediFoam: A general-purpose, open-source CFD-DEM solver for particle-laden flow with emphasis on sediment transport. Comput. Geosci. 2016, 89, 207-219. [CrossRef]

11. Chen, F.; Drumm, E.C.; Guiochon, G. Coupled discrete element and finite volume solution of two classical soil mechanics problems. Comput. Geotech. 2011, 38, 638-647. [CrossRef]

12. Zhao, J.; Shan, T. Coupled CFD-DEM simulation of fluid-particle interaction in geomechanics. Powder Technol. 2013, 239, 248-258. [CrossRef]

13. Xu, S.; Sun, R.; Cai, Y.; Sun, H. Study of sedimentation of non-cohesive particles via cfd-dem simulations. Granul. Matter 2018, 20, 4. [CrossRef]

14. Tao, H.; Tao, J. Quantitative analysis of piping erosion micro-mechanisms with coupled CFD and DEM method. Acta Geotech. 2017, 12, 1-20. [CrossRef]

15. Sun, H.; Xu, S.; Pan, X.; Shi, L.; Cai, Y. Investigating the jamming of particles in a three-dimensional fluid-driven flow via coupled CFD-DEM simulations. Int. J. Multiph. Flow 2019, 114, 140-153. [CrossRef]

16. Xu, S.; Sun, H.; Cai, Y.; Geng, X. Studying the orifice jamming of a polydispersed particle system via coupled cfd-dem simulations. Powder Technol. 2020, 368, 308-322. [CrossRef]

17. Adrian, R.J. Particle-imaging techniques for experimental fluid-mechanics. Annu. Rev. Fluid Mech. 1991, 23, 261-304. [CrossRef]

18. Yuan, B.; Sun, M.; Wang, Y.; Zhai, L.; Luo, Q. Full 3D displacement measuring system for 3D displacement field of soil around a laterally loaded pile in transparent soil. Int. J. Geomech. 2019, 19, 04019028. [CrossRef]

19. Ahmed, M.; Iskander, M. Evaluation of tunnel face stability by transparent soil models. Tunn. Undergr. Space Technol. 2012, 27, 101-110. [CrossRef]

20. Zhang, Z.; Tao, F.; Han, J.; Ye, G.; Cheng, B.; Xu, C. Arching development in transparent soil during multiple trapdoor movement and surface footing loading. Int. J. Geomech. 2021, 21, 04020262. [CrossRef]

21. Pan, X.; Zhou, L.; Sun, H.; Cai, Y.; Shi, L.; Yuan, Z. Vacuum loading test for high moisture content slurry using particle image velocimetry. J. Zhejiang Univ. Eng. Sci. 2020, 54, 1078-1085.

22. Cai, Y. Consolidation mechanism of vacuum preloading for dredged slurry and anti-clogging method for drains. Chin. J. Geotech. Eng. 2021, 43, 201-225.

23. Richardson, J.F.; Zaki, W.N. Sedimentation and Fluidization: Part, I. Chem. Eng. Res. Des. 1997, 75, S82-S100. [CrossRef]

24. Narejo, D.B. Opening size recommendations for separation geotextiles used in pavements. Geotext. Geomembr. 2003, 21, 257-264. [CrossRef]

25. Liu, L.; Chu, C. Modeling the slurry filtration performance of nonwoven geotextiles. Geotext. Geomembr. 2006, 24, 325-330. [CrossRef]

26. Tang, L. Pore Size Characteristics and Filtration Properties of Geotextiles Subjected to Tensile Strains; Zhejiang University: Hangzhou, China, 2014 